\title{
МАТЕМАТИЧЕСКИЕ МОДЕЛИ ПРОЦЕССА ИСТЕЧЕНИЯ ЖИДКОСТИ ИЗ РЕЗЕРВУАРОВ
}

Зотов B.A.

(МАТИ ии. К. Э. ЦИолковского)

Исследование законов истечения жидкости из резервуаров через отверстия относится к классу задач прикладной гидродинамики, пироко используемых в геофизике.

Таковыми являются проблемы нефтепромысловой механики, инженерной геофизики, подземной гидрогеологии и другие.

Математические модели, адекватно описывающие указанные явления, должны учитывать не только форму резервуара и расположение отверстий, но и свойства жидкости и материалов емкости.

Рассмотрим вертикально расположенный резервуар высоты $\mathrm{H}$, полностью заполненный жидкостью и стенки которого состоят из абсолютно упругого материала с заданыыми отверстиями площади $\sigma_{i}$ на дне и $\rho_{j}$ на боковой поверхности, расположенных на высоте $H_{j}$.

Определение закона изменения уровня жидкости $h(t)$ в таком резервуаре сводятся к решению системы нелинейных обыкновенных дифференциальных уравнений вида

$$
\begin{aligned}
& S(h) \frac{d h}{d t}=-\mu\left[\sum_{i=1}^{n} \sigma_{i}(t) \cdot \sqrt{2 g h}+\sum_{j=1}^{m} \rho_{j}(t) \cdot \sqrt{2 g\left(h-H_{j}\right)}\right] \\
& h(0)=H_{k-1} ; \quad 0<t<t_{j} ; \quad \mathrm{k}=1,2, \ldots, m+1
\end{aligned}
$$

где $S(h)$ - площадь поперечного сечения резервуара; $\mu$ - коэффичиент расхода жидкости (для воды $\mu=0,62$ ); $g$ - ускорение свободного падения $\left(g=9,8 m / c^{2}\right) ; n$ и $m$ - количество отверстий на дне и стенке.

Полное время истечения жидкости из резервуара равно

$$
T=t_{1}+t_{2}+\ldots+t_{m}+t_{m+1}
$$

где интервалы времени $t_{j}$ вычисляются из условий

$$
h\left(t_{j}\right)=H_{j}
$$

В обшем случае система уравнений (1) не интегрируема в квадратах.

Поэтому выбор гидродинамических параметров резервуара возможен только в результате численного решения системы уравнений (1).

Однако в отдельных случаях система уравнений (1) допускает точные аналитические решения, позволяющие делать качественные выводы о характере истечения жидкости из резервуаров с отверстиями.

Например, время $T$ истечения жидкости из цилиндра только через систему $n$ отверстий на дне удовлетворяет условкю

$$
\frac{1}{T}=\sum_{i=1}^{n} \frac{1}{T_{i}}
$$

где $T_{i}$ - время истечения всего объема жидкости через одно отверстие.
Процесс истечения жидкости из цилиндра через одно отверстие на дне носит монотонный характер (без точки перегиба), а из шара - состоит из быстрой и медленной фаз. Гранища раздела фаз (точка перегиба) расположена на высоте

$$
h=\frac{2}{3} R \text {, }
$$

где $R$ - радиус шара.

При этом полное время $T$ истечения жкдкости из пара состоит из времени истечения верхней $t_{1}$ и нижней $t_{2}$ половин шара, которые относятся, как

$$
t_{1}: t_{2} \approx 3: 5 \text {. }
$$

Время истечения одинакового объема жидкости из полностью наполненных шара радиуса $R$ и цилиндра радиуса $R$ и высоты $\frac{4}{3} R$ соотносятся в виде пропорции

$$
\tau_{1}: \tau_{2} \approx 2: 5 \text {. }
$$

Время истечения жидкости из цилиндра высоты $H_{0}$ через два одинаковых отверстия, расположенных по одному на дне и на боковой поверхности на высоте $H_{1}$, равно

$$
T=\frac{1}{3} T_{1}\left(2+p^{3}-\left(p^{2}-1\right)^{3 / 2}\right),
$$

где $T_{0}$ и $T_{1}$ - время истечения жидкости из цилипдров высоты $H_{0}$ и $H_{1}$ через отверстие на дне ; $p=T_{0} / T_{1}$ - безразмерный параметр.

Указанные особенности процесса истечения жидкости из резервуаров с отверстиями позволяют эффективно управлять соответствующими гидродинамическими процессами.

\section{ЛИТЕРАТУРА}

Кочин Н.Е., Кибель И.А., Розе Н.В. Теоретическая гидромеханика, Ч. 1, 4.2, - М.: Гостеортехиздат, 1948.

Шанин В.М. Гидромеханика. - М.: Высшая школа, 1990.

Нигматулин Рс.И., Соловьев А.А. Физическая гидромеханика. M.: ГЭОТАР, 2005 